\title{
The Desire to Explain Phenomenon: Hospital Nursing Staff's Familiarity and Perceived Relevance of Superstitions
}

\author{
Melissa Thomassy, Ashley Peacock, Amber Leone, Heather Hornbostel, \\ Peggy Ward-Smith ${ }^{*}$ \\ North Kansas City Hospital, 2800 Clay Edwards Drive, North Kansas City, MO, USA \\ Email: *wardsmithp@umkc.edu
}

How to cite this paper: Thomassy, M., Peacock, A., Leone, A., Hornbostel, H., \& Ward-Smith, P. (2021). The Desire to Explain Phenomenon: Hospital Nursing Staff's Familiarity and Perceived Relevance of Superstitions. Open Journal of Social Sciences, 9, 204-218.

https://doi.org/10.4236/jss.2021.99015

Received: August 12, 2021

Accepted: September 10, 2021

Published: September 13, 2021

Copyright $\odot 2021$ by author(s) and Scientific Research Publishing Inc. This work is licensed under the Creative Commons Attribution International License (CC BY 4.0).

http://creativecommons.org/licenses/by/4.0/

(c) (i) Open Access

\begin{abstract}
The use of superstitions, in healthcare settings, is often used to understand uncontrollable events. In order to describe the knowledge and clinical relevance of superstitions, survey data were collected from nursing staff who provide direct patient care. Using a research-based, study-specific survey, the aim of this study was to describe the knowledge and clinical relevance of superstitions among nurses who provide direct patient care in a hospital setting. These data were analyzed to describe the study population, along with their knowledge and clinical relevance of superstitions, and compare the responses based on self-disclosure of superstitiousness. Participants that described themselves as superstitious reported a greater propensity for superstitions to be clinically relevant. Less education and younger age increased one's use of superstitions in a clinical setting. The use of superstitions provides a coping mechanism for healthcare providers and a format to explain and understand uncontrollable events.
\end{abstract}

\section{Keywords}

Superstitions, Knowledge, Clinical Relevance, Nursing Staff, Survey Data

\section{Introduction}

Superstition, as a noun, is believed to derive from two Latin words. Superstitio, which means "to stand over in awe," and from superstes, which means "outliving" or "surviving." Together, these words describe ideas and/or beliefs that remain long after their original intention has been forgotten (Stapelberg, 2014). Originally, superstitions were used to describe natural phenomena (thunderstorms) 
or understand events that could not be controlled (illnesses). Taher and associates (2020) theorize that people become superstitious when death, illness, or adverse events are encountered. In these situations, the superstitions are used to relieve inner turmoil caused by fear, anxiety, and feelings of failure. Superstitions prevented ignorance for they explained events and minimized the fear of the unknown. As a result of scientific advances, Stapelberg posits that a belief in superstitions, as a way of thinking, is outmoded. Yet the use, and belief in, superstitions exist. In the $21^{\text {st }}$ Century, Matute and associates (2011) summarize the plethora of research which documents the tendency to see causal relationships where none exist. Research by Griffiths and associates (2019) demonstrates a direct relationship between a person's self-reported superstitions to the likelihood of experiencing them and the ability of the superstition to guide behavior.

Superstitions have been identified as activities used in situations where there is a loss of control (Whitson \& Galinsky 2008). The structure afforded by the superstition provides a sense of comfort, allowing the individual to cope with the situation, and provide an explanation, even if that explanation is illusionary. These illusions provide a sense of structure to an otherwise chaotic environment. Higher levels of intuitive thinking, along with lower levels of analytical thinking, have been posited to results in superstitious beliefs (Vyse, 1997). Thus, superstitions may be used as a coping mechanism to manage stress, anxiety, and uncertainty in situations where control is not possible. This description aligns with the experience of healthcare professionals during the COVID-19 pandemic. A review of the literature failed to identify a link between superstitious beliefs and coping during a healthcare crisis. Thus, this research was undertaken to determine if any correlation exists.

\section{Problem of the Study}

Superstitions provide a mechanism to attain control or manage events, especially when one feels helpless. The worldwide challenges of the COVID-19 pandemic resulted in uncontrollable healthcare challenges. These challenges included uncertainty with respect to the appropriate treatment(s) for those infected, ambiguity in the mode(s) of transmission, and the ability to protect oneself, along with staffing and equipment shortages. For healthcare providers, superstitions may provide a necessary coping mechanism when situations become, and remain, out of one's control. The purpose of this survey study was to describe the level of familiarity with superstitions and the relevance to clinical practice among nursing staff employed at an acute care health facility.

\section{Study Objectives}

- To describe the level of familiarity nursing staff have specific to various types of superstitions.

- To describe the strength of these superstitions to influence clinical care provided. 
- To identify differences in knowledge or relevance of superstitions based on demographic data.

- To correlate one's self-reported superstitiousness stance to knowledge and/or relevance to clinical practice.

This study aims to describe the level of familiarity and relevance to clinical practice of superstitions.

\section{Study Significance}

- These data illustrate the role of superstitions as a coping mechanism in healthcare situations that are beyond one's control.

- Describe which superstitions are well-known and which superstitions influence care.

\section{Literature Review}

Superstitions, defined by Huque and Chowdhurry (2007), are "beliefs about particular events that cannot be explained by scientific reasoning” (p. 18). These beliefs have been prevalent throughout history (Faiza, 2018) and have been identified as a source of behavior (Hirshleifer et al., 2018). Taher and associates (2020) speculate that superstitions have pronounced psychological-cognitive effects that guide beliefs and actions. Luck, chance, or coincidences are concepts used to define an experience that is improbable, and as such they differ from superstitions. Superstitions are often used to bridge the gap present when events cannot be explained through scientific reasoning (Parnell et al., 2012).

Culture has a definite influence on the content of superstitions, along with the belief and behavioral consequences of these events. While every culture has specific superstitions (Carlson et al., 2009), demographic research has identified variables that influence beliefs and the use of superstitions to guide behavior. Research by Buhrmann and Zaugg (1981) identified females as having higher levels of superstition than males in the general population. Yet when comparing gender beliefs among athletes, male hockey players report a higher engagement in superstitious behaviors than female hockey players (Neil, Anderson, \& Sheppard, 1981). Yet, female basketball players were more likely that their male counterparts to report superstitious beliefs and behavior (Buhrmann \& Zaugg, 1981). Ramezani and colleagues (2016) failed to identify differences in superstition beliefs based on education; participants with the lower level of education reported similar beliefs as highly educated individuals. Age also failed to influence superstitious beliefs or behavior (Torgler, 2007).

Within healthcare, Hong (2018) describes the cultural stigma that impacts health communication and the euphuisms used to talk about death. An example of this is provided by Kuhl (2003) as the fear of "talking about death beckons it" ( $\mathrm{p} \mathrm{vx}$ ). Results from a descriptive study by Wong (2012) identified death anxiety as prevalent among Chinese undergraduates who also described themselves as very superstitious. Superstitions in healthcare appear to have positive and negative ef- 
fects. Taher et al. (2020) explain "for instance, a chronically ill person blames his illness on fate and destiny, and his stress is thus reduced, and he can even be satisfied with living with a chronic disease. Nonetheless, this thinking makes him not pursue his treatment and care and he will thus witness adverse effects on his body and soul in the long term, which is regarded as a negative consequence" (p. 1328). In earlier research, Taher et al. (2015) determined that patients who held several superstitious beliefs and had a diagnosis of hypertension failed to adhere to their plan of care. This correlation is supported by the research results of $\mathrm{Ab}$ redari et al. (2015) and Omeje and Nebo (2011) among diabetic patients.

Peterson (1978) provides a theoretical framework useful for categorizing superstitions. Based on Skinner's (1953) behavioral work, which linked superstitious rituals to the erroneous perception of a correlation between personal experience and behavior. Peterson then placed superstitions into self-oriented categories. These categories, 1) unspecified bad (UB), 2) unspecified good (UG), 3) protective rituals (PR), or 4) specific consequences (SC) served to place the superstition within a belief, thus providing a purpose for the activity. This framework was used to format the survey instrument used in the present study. Vyse (1997) states that "if there is one universal truth about superstitions, it is that superstitious behavior emerges as a response to uncertainty to circumstances that are inherently random and uncontrollable" (p. 201).

Among healthcare providers, superstitions are portrayed as interventions used as coping mechanisms aimed at managing stress, anxiety, or discomfort in situations where control is not possible. Superstitions surrounding illness and death, for nurses, are used to make sense of the death and alleviate the anxiety and feeling of failure. When science and logical explanations fail to explain the death, superstitious beliefs may relieve the inner turmoil and anxiety (Kashdan \& Rottenberg, 2010). Death superstitions may be categorized as preventative, or activities aimed toward preventing the death, or ritualistic, which are activities aimed at easing the transition to death for the patient. Superstitions provide a mechanism to correlate one event to another when a natural or scientific reason fails to exist (Taher et al., 2020). While chance, luck, and consequences are close concepts to superstition, superstition has a cultural foundation toward understanding unexplainable events and rationalizing behavior. Thus, chance may be a onetime event, luck tends to affect behavior when its presence is perceived (Parnell et al., 2012), and consequences are used to illuminate a result. Taher et al. (2020) posit that the recognition of superstitions, as a motivator for decisions and behaviors, provides a method to support the individual in situations that are uncontrollable.

\section{Study Hypothesis}

- Descriptive research aims to describe specific behaviors or attributes, Study hypothesis one: To describe the study population using demographic data, the social desirability response, the self-disclosed ranking of superstitiousness, 
and the locus of control.

- Study hypothesis two: To explore and describe the knowledge and relevance of superstitions to clinical practice among nurses in an acute care hospital.

- Study hypothesis three: To correlate these responses to the perceived self-described level of superstition, the self-reported locus of control, and specific demographic data.

\section{Methodology of Study}

This descriptive study used survey data to explore and describe the knowledge and relevance of superstitions among nursing staff (registered nurses [RN] and unlicensed providers [UAP]) who provide direct patient care in an acute healthcare setting. Data were obtained via a survey, administered using a web-based format, which provided confidentiality and anonymity.

A study invitational email was sent to each potential participant from the Chief Nursing Officer (CNO) at the study site. This letter described the purpose of the study, the time requirement associated with participation, what would be done with the responses, the known and potential risks associated with participation, a statement clarifying that participation was voluntary, employment status will not be affected if the decision is to not participate, that study conclusions will be reported in aggregate format only, and contact people, with phone numbers, were provided if further information was desired, or if there were study participation questions. Embedded within the email was a live link to the survey tool; access to the study survey required clicking on this link. The ability to complete the survey during multiple timeframes was feasible, skipping items where the preference was not to provide a response was possible. As the CNO, access to individual emails was supported by the job responsibilities; email was the preferred method of secure communication at the study site.

Study data were collected over an eight-week period during the winter months of 2020-2021 (the initial peak of the COVID-19 pandemic). A study invitational email, which detailed the study aim, purpose, known risks, and estimated time required for participation, was sent to each participant. If participation was desired, the link to the survey was embedded within this email. The decision to obtain data using an online format was guided by the ability to invite all potential participants regardless of shift or frequency of working, the ability to complete the survey at a time and place convenient for the participant, and the ability to ensure data were confidential and anonymous. The study was approved, as exempt research, by the hospital's Institutional Review Committee, where it was determined that participation would encompass approximately 10 minutes.

\section{The Study Tools}

Guided by the literature and anecdotal experiences of the members of the Research and Innovations Nursing Shared Governance Council at the study site, an 18-item, 3-point Likert response survey was developed. Formatted using the self- 
oriented categories described by Peterson (1978) and the survey development depicted by Chukkali and Dey (2020), an initial pool of 37 superstitious were identified through the literature, nursing-specific websites and blogs, and the lived experiences of the Council members. These were reviewed by the members of the Council for familiarity and appropriateness to the setting; 18 were selected for inclusion. These items were placed within the framework described by Peterson (1978) as 1) unspecified bad, 2) unspecified good, 3) protected ritual, and 4) specific consequence. The first subscale had one general superstition item and five nursing specific items; each subsequent subscale had one general superstition item and three nursing specific items. One open-ended response item allowed each participant to add and describe a superstition they had either knowledge or an awareness of. The study survey is displayed in Table 1.

In addition to these items, each participant self-described their level of superstitiousness guided by four possible responses (very superstitious, superstitious, ambivalent toward superstitious, not superstitious at all). The three items assessed each participant's locus of control and were used to develop sub-populations

Table 1. Study survey.

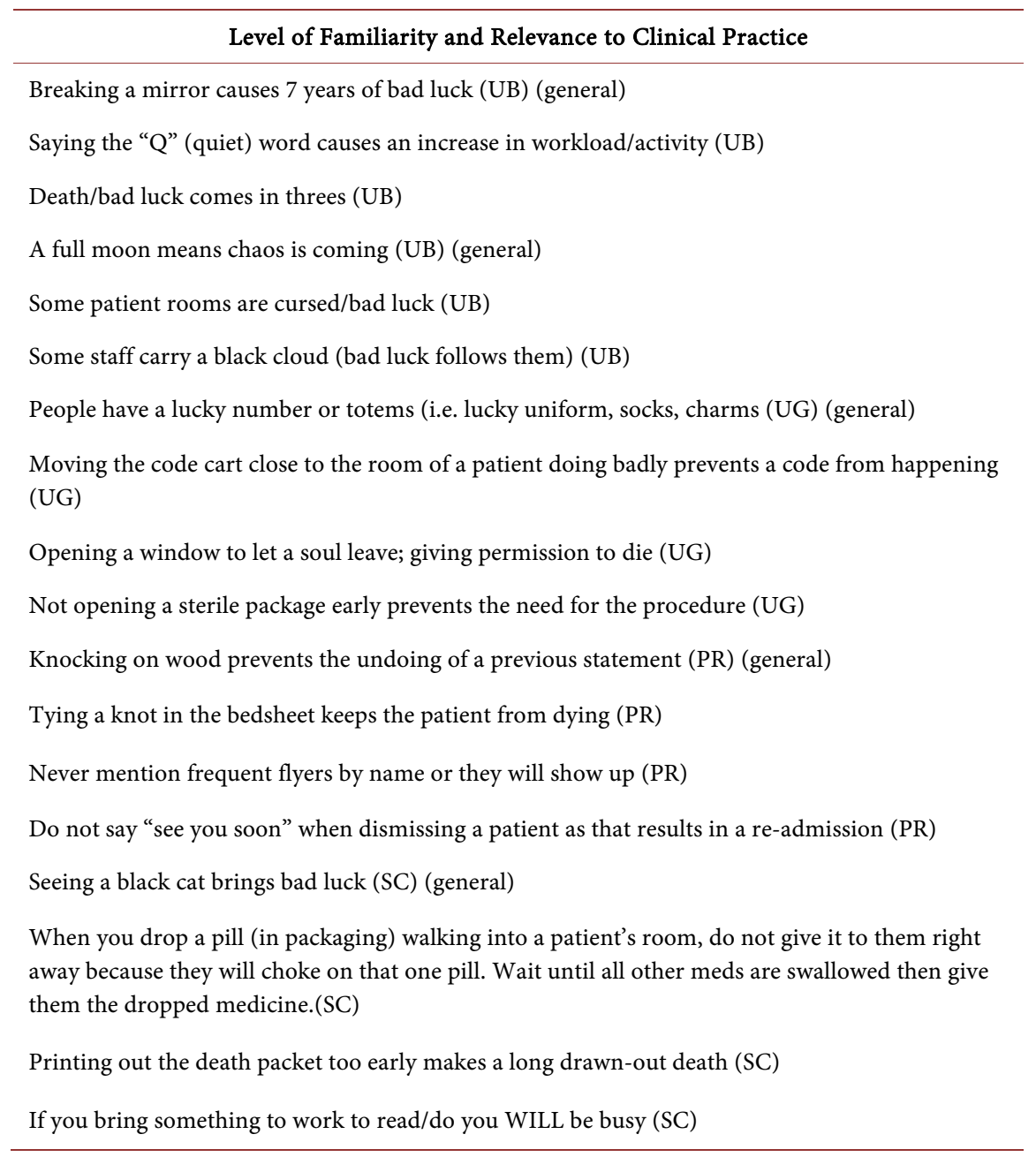


(high level of control and low level of control). One social desirability item was included in the survey and used only to determine if bias was present in participant responses (Phillips \& Clancy, 1972). Demographic data were collected, which was used to describe the study population and to identify trends based on these variables.

\section{Limits of Analysis Tools}

- Objective limits: A description of the familiarity of superstitious beliefs among nurses, the relevance of these beliefs to their clinical practice or workplace activities.

- Human limits: Nurses employed at the study site who voluntarily provided data.

- Spatial limits: An acute care health facility located in the Midwest region of the United States of America.

- Temporal limits: The winter months of 2020-2021.

\section{Data Analysis and Discussion of Results}

\subsection{Characteristics of the Study Sample-Study Hypothesis One-To Describe the Study Population Using Demographic Data, the Social Desirability Response, the Self-Disclosed Ranking of Superstition, and the Locus of Control}

The study population consisted of adult volunteers, employed at the study site, in a nursing position (RN or UAP). Human Resource data were used to initially identify the study population. Inclusion criteria limited participation to those in nursing job categories. Exclusion criteria eliminated individuals not in a nursing position in which they provide direct patient care. The study participation invite was sent to the password protected; employer supported email of 1172 individuals. Of these individuals, 502 completed and submitted the survey. This represents a $42.8 \%$ participation rate. Results from a power analysis, using the 18-Likert responses in the study survey, calculate to an $80 \%$ confidence interval, with a $5 \%$ (0.05) risk of a Type II error.

Demographic characteristics of the participants are presented in Table 2. In general, the majority of the participants were female (92.2\%), employed as a registered nurse (RN) (80.73\%), in a full-time position (72.8\%), working day shifts (7A - 7P) (67\%), and having earned a Bachelor's Degree (58\%). Being employed in healthcare was almost evenly split with $54.4 \%$ of the population reporting at least 10 years of experience. Fifty-three percent of the study population reported their age to be under 40 years. The largest percent of participants (19.6\%) reported being between the ages of 25 to 30 years old, with those either 46 to 50 or over the age of 60 years encompassing the smallest population samples, at $7.4 \%$ each.

Responses to the Social Desirability item were calculated to determine if the responses were skewed, based on the ability to provide data free of social or cultural pressure. These data indicate a slight propensity for the study population 
Table 2. Demographic characteristics of the participants.

\begin{tabular}{|c|c|c|c|}
\hline Property & Category & Number & Ratio \\
\hline \multirow{3}{*}{ Gender categories } & Male & & $8.0 \%$ \\
\hline & Female & & $92.2 \%$ \\
\hline & Non-disclosed & & $0.2 \%$ \\
\hline \multirow{2}{*}{ Job classification } & Registered Nurse (RN) & 352 & $80.7 \%$ \\
\hline & Unlicensed Providers (UAP) & 84 & $19.3 \%$ \\
\hline \multirow{3}{*}{ Job status } & Full time & 356 & $72.8 \%$ \\
\hline & Part time & 80 & $16.4 \%$ \\
\hline & As needed/on call (PT or PTOC) & 53 & $10.8 \%$ \\
\hline \multirow{3}{*}{ Shift worked } & Days (7A - 7P) & 334 & $67 \%$ \\
\hline & Nights (7P - 7A) & 134 & $26.8 \%$ \\
\hline & Mixed or variable & 31 & $6.2 \%$ \\
\hline \multirow{6}{*}{$\begin{array}{l}\text { Years of employment } \\
\text { at study site }\end{array}$} & Less than 1 year & 16 & $3 \%$ \\
\hline & $1-5$ years & 110 & $22 \%$ \\
\hline & $6-10$ years & 98 & $19.4 \%$ \\
\hline & $11-15$ years & 62 & $12.3 \%$ \\
\hline & $16-20$ years & 49 & $9.7 \%$ \\
\hline & More than 20 years & 167 & $33.6 \%$ \\
\hline \multirow{6}{*}{ Level of education } & High School Degree & 30 & $6 \%$ \\
\hline & Diploma & 40 & $8 \%$ \\
\hline & Associates Degree & 99 & $19.8 \%$ \\
\hline & Bachelors Degree & 290 & $58 \%$ \\
\hline & Masters Degree & 37 & $7.4 \%$ \\
\hline & Doctorate Degree & 4 & $0.8 \%$ \\
\hline \multirow{9}{*}{ Age in categories } & Under 25 years & 50 & $10 \%$ \\
\hline & $25-30$ years & 98 & $19.6 \%$ \\
\hline & $31-35$ years & 67 & $13.4 \%$ \\
\hline & 36 - 40 years & 50 & $10 \%$ \\
\hline & $41-45$ years & 60 & $12 \%$ \\
\hline & 46 - 50 years & 38 & $7.4 \%$ \\
\hline & 51 - 55 years & 51 & $10.2 \%$ \\
\hline & $56-60$ years & 50 & $10 \%$ \\
\hline & Over 60 years & 38 & $7.4 \%$ \\
\hline
\end{tabular}

(71.5\%) to disagree with the item, reflective of little societal pressure to conform. The Locus of Control items were calculated to describe the desire for these study participants to control a situation (70.9\%), the ability to recognize that control is not always possible (88.7\%), and how superstitions are used in uncontrollable situations (64.3\%). Responses reveal a study population that would like to be in control, yet are aware that this is often not possible, and that there are situations in which prevention is not feasible. These results are displayed in Table 3. Results of the self-reported ranking of superstition describe a study population in which one-third report being superstitious, at some level. Slightly less than one- 
Table 3. Social desirability and superstitious locus of control survey responses.

\begin{tabular}{lccc}
\hline \multicolumn{1}{c}{ ITEM } & Response & Number & Ratio \\
\hline $\begin{array}{l}\text { I sometimes think when people have misfortune } \\
\text { they only got what they deserved (Social Desirability) }\end{array}$ & Yes & 137 & $28.5 \%$ \\
\hline $\begin{array}{l}\text { The ability to be on control of any situation } \\
\text { is important to me (Locus of Control) }\end{array}$ & Yes & 339 & $71.5 \%$ \\
\hline $\begin{array}{l}\text { Some things are going to happen and there is nothing } \\
\text { you can do to prevent them (Locus of Control) }\end{array}$ & Nes & 139 & $29.1 \%$ \\
\hline $\begin{array}{l}\text { Using superstition helps maintain some perception } \\
\text { of control over a situation (Locus of Control) }\end{array}$ & No & 54 & $88 \%$ \\
\hline
\end{tabular}

fourth describe themselves as not superstitious at all. Almost half the study population (46.1\%) is ambivalent toward superstitions. These results are displayed in Table 4.

\subsection{Testing the Hypotheses of the Study}

Study hypothesis two: To explore and describe the knowledge and relevance of superstitions to clinical practice among nurses in an acute care hospital. Responses to the level of familiarity and relevancy survey items underwent descriptive analyses. Each item was assessed for both level of familiarity and relevancy, providing the ability to detect, and separate, knowledge of the superstition to those guiding clinical practice. These results are displayed in Table 5. Results indicate that, in general, these study participants were familiar with generic superstitions readily available within the culture. The ability of these generic superstitious to have relevancy in healthcare varied. Items assessing UB superstitions were denoted to have clinical relevance, while the UG and PR items were neutral in their clinical relevance, and the SC item was not relevant to clinical practice. There were two healthcare-specific items in which greater than $75 \%$ of the population were very familiar with: 1) saying the Q (quiet) word causes an increase in workload/activity and 2) death /bad luck comes in threes. There were three items in which greater than $75 \%$ of the study population reported being unfamiliar with: 1) tying a knot in the bedsheet keeps the patient from dying, 2) when you drop a pill (in packaging) walking into a patient's room, do not give it to them right away because they will choke on that one pill, and 3) printing out the death packet too early makes a long drawn-out death. There were no healthcare-specific items described as very relevant to clinical practice. Healthcarespecific items described as irrelevant to clinical practice included: 1) not opening a sterile package early prevents the need for the procedure, 2) tying a knot in the bedsheet keeps the patient from dying, 3) do not say "see you soon" when dismissing a patient as that results in a re-admission, 4) when you drop a pill (in packaging) walking into a patient's room, do not give it to them right away because they will choak on that one pill, and 5) printing out the death package too early makes a long, drawn-out death. 
Table 4. Superstitious self-description.

\begin{tabular}{ccc}
\hline ITEM & Number & Ratio \\
\hline I am very superstitious & 12 & $2.5 \%$ \\
I am superstitious & 159 & $33.1 \%$ \\
I am ambivalent toward superstitions & 221 & $46.1 \%$ \\
I am not superstitious at all & 88 & $18.3 \%$ \\
\hline
\end{tabular}

Table 5. Familiarity and clinical relevance survey, differences between those self-describing themselves as superstitious.

\begin{tabular}{|c|c|c|c|c|c|c|}
\hline \multirow[b]{2}{*}{$\underline{\text { Item }}$} & \multicolumn{3}{|c|}{ Familiarity } & \multirow{2}{*}{$\begin{array}{l}\text { Clinical } \\
\text { Irrelevant }\end{array}$} & \multicolumn{2}{|c|}{ Relevance } \\
\hline & Unfamiliar & Familiar & $\begin{array}{c}\text { Very } \\
\text { Familiar }\end{array}$ & & $\begin{array}{l}\text { Somewhat } \\
\text { Relevant }\end{array}$ & $\begin{array}{c}\text { Very } \\
\text { Relevant }\end{array}$ \\
\hline Breaking a mirror causes 7 years of bad luck (UB) (general) & $\begin{array}{l}3.9 \% \\
(3 \%)\end{array}$ & $\begin{array}{l}16.8 \% \\
(18 \%)\end{array}$ & $\begin{array}{l}79.3 \% \\
(79 \%)\end{array}$ & $\begin{array}{c}73.6 \% \\
(18.5 \%) \\
-57.8\end{array}$ & $\begin{array}{r}18.7 \% \\
(29 \%) \\
+10.3\end{array}$ & $\begin{array}{c}7.7 \% \\
(52.5 \%) \\
+44.8\end{array}$ \\
\hline $\begin{array}{l}\text { Saying the "Q" (quiet) word causes an } \\
\text { increase in workload/activity (UB) }\end{array}$ & $\begin{array}{c}5.1 \% \\
(3.6 \%)\end{array}$ & $\begin{array}{c}8.8 \% \\
(4.2 \%)\end{array}$ & $\begin{array}{c}86.0 \% \\
(92.2 \%)\end{array}$ & $\begin{array}{c}21.2 \% \\
(6.8 \%) \\
-14.1\end{array}$ & $\begin{array}{c}25.5 \% \\
(14.8 \%) \\
-10.7\end{array}$ & $\begin{array}{c}53.3 \% \\
(\mathbf{7 8 . 4} \%) \\
+25.1\end{array}$ \\
\hline Death/bad luck comes in threes (UB) & & $\begin{array}{l}14.0 \% \\
(9.6 \%)\end{array}$ & $\begin{array}{c}81.7 \% \\
(86.2 \%)\end{array}$ & $\begin{array}{c}30.3 \% \\
(14.2 \%) \\
-16.1\end{array}$ & $\begin{array}{c}32.7 \% \\
(28.4 \%) \\
-4.3\end{array}$ & $\begin{array}{c}37.0 \% \\
(57.4 \%) \\
+20.4\end{array}$ \\
\hline A full moon means chaos is coming (UB) (general) & $\begin{array}{l}1.5 \% \\
(0.6 \%)\end{array}$ & $\begin{array}{c}4.1 \% \\
(3.6 \%)\end{array}$ & $\begin{array}{c}93.8 \% \\
(95.8 \%)\end{array}$ & $\begin{array}{c}13.8 \% \\
(3.7 \%) \\
-10.1\end{array}$ & $\begin{array}{c}23.7 \% \\
(13.6 \%) \\
-10.1\end{array}$ & $\begin{array}{c}62.5 \% \\
(82.7 \%) \\
+20.2\end{array}$ \\
\hline Some patient rooms are cursed/bad luck (UB) & $\begin{array}{l}20.0 \% \\
(2.6 \%)\end{array}$ & $\begin{array}{c}24.7 \% \\
(21.5 \%)\end{array}$ & $\begin{array}{c}55.3 \% \\
(65.9 \%)\end{array}$ & $\begin{array}{c}48.4 \% \\
(26.3 \%) \\
-22.2\end{array}$ & $\begin{array}{c}27.6 \% \\
(31.2 \%) \\
+3.6\end{array}$ & $\begin{array}{c}24.0 \% \\
(42.5 \%) \\
+18.5\end{array}$ \\
\hline Some staff carry a black cloud (bad luck follows them) (UB) & $\begin{array}{c}17.4 \% \\
(12.0 \%)\end{array}$ & $\begin{array}{c}26.2 \% \\
(24.5 \%)\end{array}$ & $\begin{array}{c}56.4 \% \\
(63.5 \%)\end{array}$ & $\begin{array}{c}39.6 \% \\
(21.1 \%) \\
-18.5\end{array}$ & $\begin{array}{c}30.4 \% \\
(37.3 \%) \\
+6.9\end{array}$ & $\begin{array}{c}30.0 \% \\
(41.6 \%) \\
+11.6\end{array}$ \\
\hline $\begin{array}{l}\text { People have a lucky number or totems } \\
\text { (i.e. lucky uniform, socks, charms (UG) (general) }\end{array}$ & $\begin{array}{l}13.4 \% \\
(9.0 \%)\end{array}$ & $\begin{array}{c}26.1 \% \\
(27.5 \%)\end{array}$ & $\begin{array}{c}60.5 \% \\
(63.5 \%)\end{array}$ & $\begin{array}{c}60.0 \% \\
(37.7 \%) \\
-22.3\end{array}$ & $\begin{array}{c}26.9 \% \\
(39.5 \%) \\
+12.6\end{array}$ & $\begin{array}{c}13.1 \% \\
(22.8 \%) \\
+9.4\end{array}$ \\
\hline $\begin{array}{l}\text { Moving the code cart close to the room of a patient } \\
\text { doing badly prevents a code from happening (UG) }\end{array}$ & $\begin{array}{c}44.5 \% \\
(37.6 \%)\end{array}$ & $\begin{array}{c}18.3 \% \\
(19.9 \%)\end{array}$ & $\begin{array}{c}37.2 \% \\
(42.5 \%)\end{array}$ & $\begin{array}{c}57.8 \% \\
(42.6 \%) \\
-15.2\end{array}$ & $\begin{array}{c}23.2 \% \\
(27.1 \%) \\
+3.9\end{array}$ & $\begin{array}{c}19.0 \% \\
(30.3 \%) \\
+11.3\end{array}$ \\
\hline $\begin{array}{l}\text { Opening a window to let a soul leave; } \\
\text { giving permission to die (UG) }\end{array}$ & $\begin{array}{c}27.7 \% \\
(19.2 \%)\end{array}$ & $\begin{array}{c}28.4 \% \\
(29.3 \%)\end{array}$ & $\begin{array}{c}43.9 \% \\
(51.5 \%)\end{array}$ & $\begin{array}{c}62.4 \% \\
(42.8 \%) \\
-19.6\end{array}$ & $\begin{array}{c}19.5 \% \\
(28.6 \%) \\
+9.1\end{array}$ & $\begin{array}{c}18.1 \% \\
(28.6 \%) \\
+10.5\end{array}$ \\
\hline $\begin{array}{l}\text { Not opening a sterile package early prevents the need for the } \\
\text { procedure (UG) }\end{array}$ & $\begin{array}{c}69.2 \% \\
(58.4 \%)\end{array}$ & $\begin{array}{c}18.5 \% \\
(23.5 \%)\end{array}$ & $\begin{array}{c}12.3 \% \\
(\mathbf{1 8 . 1} \%)\end{array}$ & $\begin{array}{c}78.6 \% \\
(64.2 \%) \\
-14.4\end{array}$ & $\begin{array}{c}15.3 \% \\
(22.8 \%) \\
+7.5\end{array}$ & $\begin{array}{c}6.1 \% \\
(13.0 \%) \\
+6.9\end{array}$ \\
\hline $\begin{array}{l}\text { Knocking on wood prevents the } \\
\text { undoing of a previous statement (PR) (general) }\end{array}$ & $\begin{array}{c}3.4 \% \\
(1.8 \%)\end{array}$ & $\begin{array}{l}10.1 \% \\
(9.0 \%)\end{array}$ & $\begin{array}{c}86.5 \% \\
(89.2 \%)\end{array}$ & $\begin{array}{c}32.1 \% \\
(12.9 \%) \\
-19.2\end{array}$ & $\begin{array}{c}30.7 \% \\
(27.8 \%) \\
-2.9\end{array}$ & $\begin{array}{c}37.2 \% \\
(59.3 \%) \\
+22.1\end{array}$ \\
\hline Tying a knot in the bedsheet keeps the patient from dying (PR) & $\begin{array}{c}85.1 \% \\
(82.0 \%)\end{array}$ & $\begin{array}{c}9.2 \% \\
(10.8 \%)\end{array}$ & $\begin{array}{c}5.7 \% \\
(7.2 \%)\end{array}$ & $\begin{array}{c}86.0 \% \\
(78.4 \%) \\
-7.6\end{array}$ & $\begin{array}{c}11.1 \% \\
(17.3 \%) \\
-6.2\end{array}$ & $\begin{array}{c}2.9 \% \\
(4.3 \%) \\
+1.4\end{array}$ \\
\hline
\end{tabular}




\section{Continued}

\begin{tabular}{|c|c|c|c|c|c|c|}
\hline Never mention frequent flyers by name or they will show up (PR) & $\begin{array}{c}33.4 \% \\
(26.3 \%)\end{array}$ & $\begin{array}{c}18.1 \% \\
(16.8 \%)\end{array}$ & $\begin{array}{c}48.5 \% \\
(56.9 \%)\end{array}$ & $\begin{array}{c}49.0 \% \\
(34.6 \%) \\
-14.4\end{array}$ & $\begin{array}{c}25.2 \% \\
(24.1 \%) \\
-1.1\end{array}$ & $\begin{array}{c}25.8 \% \\
(41.3 \%) \\
+15.5\end{array}$ \\
\hline $\begin{array}{l}\text { Do not say "see you soon" when dismissing a } \\
\text { patient as that results in a re-admission (PR) }\end{array}$ & $\begin{array}{c}67.4 \% \\
(53.9 \%)\end{array}$ & $\begin{array}{c}20.5 \% \\
(26.9 \%)\end{array}$ & $\begin{array}{c}12.1 \% \\
(19.2 \%)\end{array}$ & $\begin{array}{c}76.5 \% \\
(59.3 \%) \\
-17.2\end{array}$ & $\begin{array}{c}14.5 \% \\
(25.9 \%) \\
+11.4\end{array}$ & $\begin{array}{l}9.0 \% \\
(14.8 \%) \\
+5.8\end{array}$ \\
\hline Seeing a black cat brings bad luck (SC) (general) & $\begin{array}{c}5.0 \% \\
(4.8 \%)\end{array}$ & $\begin{array}{c}19.4 \% \\
(22.3 \%)\end{array}$ & $\begin{array}{c}75.6 \% \\
(72.9 \%)\end{array}$ & $\begin{array}{c}76.0 \% \\
(61.1 \%) \\
-14.9\end{array}$ & $\begin{array}{c}14.9 \% \\
(21.0 \%) \\
+6.1\end{array}$ & $\begin{array}{l}9.1 \% \\
(14.8 \%) \\
+5.7\end{array}$ \\
\hline $\begin{array}{l}\text { When you drop a pill (in packaging) walking into a } \\
\text { patient's room, do not give it to them right away because } \\
\text { they will choke on that one pill. Wait until all other meds } \\
\text { are swallowed then give them the dropped medicine.(SC) }\end{array}$ & $\begin{array}{c}95.9 \% \\
(92.8 \%)\end{array}$ & $\begin{array}{c}3.0 \% \\
(5.4 \%)\end{array}$ & $\begin{array}{c}1.1 \% \\
(1.8 \%)\end{array}$ & $\begin{array}{c}89.4 \% \\
(81.5 \%) \\
-7.9\end{array}$ & $\begin{array}{c}7.9 \% \\
(12.3 \%) \\
+4.4\end{array}$ & $\begin{array}{c}2.7 \% \\
(6.2 \%) \\
+3.5\end{array}$ \\
\hline $\begin{array}{l}\text { Printing out the death packet too early } \\
\text { makes a long drawn-out death (SC) }\end{array}$ & $\begin{array}{c}89.0 \% \\
(83.8 \%)\end{array}$ & $\begin{array}{c}6.7 \% \\
(10.2 \%)\end{array}$ & $\begin{array}{c}4.3 \% \\
(6.0 \%)\end{array}$ & $\begin{array}{c}85.6 \% \\
(75.8 \%) \\
-9.8\end{array}$ & $\begin{array}{c}11.8 \% \\
(16.1 \%) \\
+4.3\end{array}$ & $\begin{array}{c}3.6 \% \\
(8.1 \%) \\
+4.5\end{array}$ \\
\hline If you bring something to work to read/do you WILL be busy (SC) & $\begin{array}{c}30.3 \% \\
(17.3 \%)\end{array}$ & $\begin{array}{c}22.6 \% \\
(21.0 \%)\end{array}$ & $\begin{array}{c}47.1 \% \\
(61.7 \%)\end{array}$ & $\begin{array}{c}43.0 \% \\
(22.2 \%) \\
-20.8\end{array}$ & $\begin{array}{c}27.6 \% \\
(30.9 \%) \\
+3.3\end{array}$ & $\begin{array}{c}29.4 \% \\
(46.9 \%) \\
+17.5\end{array}$ \\
\hline
\end{tabular}

Key-initial number is total study population. Bolded number in parentheses are those that described themselves as very superstitious or superstitious, italicized number with designated + or - is the difference score for those describing themselves as superstitious, compared to the study population as a whole.

Study hypothesis three: Correlating these responses to the perceived self-described level of superstition, the self-reported locus of control, and specific demographic data were performed. Guided by the self-reported responses to the level of superstitious item, responses that self-described being superstitious or very superstitious were combined. This provided a sub-group population of $35 \%$ of the overall population. Separate study groups were defined based on the superstitious response. Then, demographic data, as well as responses to the study survey, were compared between the two groups.

Demographically, there were no statistically significant differences for each variable when comparing those describing themselves as superstitious versus not being superstitious. Some trends were identified. There were no differences in describing oneself as superstitious based on gender, employment status, or shift worked. Study participants that were UAPs tended to describe themselves as superstitious more frequently (68\%) when compared to RNs. The level of education had a minor impact on superstition; among those with less than an undergraduate degree, $35.2 \%$ described themselves as superstitious, which is similar to the $34 \%$ of responses among the study population as a whole. Yet, as the level of education increased, the self-description as being superstitious decreased by $2 \%$ with a Bachelor's degree, 5\% with a Master's Degree, and 6.4\% among those with a doctorate. It seems prudent to posit that education has an associated impact on superstitious beliefs. A similar finding is noted within age; 53\% of the study population that self-described as being superstitious were under the age of 40 years, yet $59.8 \%$ of the self-reported superstitious sub-group is under the age of 40 years. 
There is an uptick in superstitious beliefs among those between the ages of 41 to 45 years, with $12 \%$ the entire study population reporting being superstitious, a number which increased to $16 \%$ within the superstitious sub-group. Other than this quirk, superstitious beliefs tend to decrease with age, with the greatest change occurring among those over age 60 years (from $7.4 \%$ to $3.2 \%$ ).

Comparing responses from the entire study population to those self-reporting superstitious beliefs (the superstitious sub-group is in bolded text) was performed. Based on a study population size of approximately 500, any $5 \%$ change was arbitrarily chosen to identify a trend. Thus, this respected the stability among most of these responses, while highlighting trends and areas where further research may be warranted. The percent differences are displayed in Table 5 and summarized as follows.

Within the level of familiarity sub-section, those that described themselves as superstitious have a greater familiarity with nine superstitions. Within the UB items, these participants 1) were more familiar with the superstition that saying the "Q" word causes an increase in workload/activity, 2) believe that some patient rooms are cursed/bad luck, and 3) think some staff carry a black cloud (bad luck follows them). Within the UG items, participants that described themselves as superstitious also were either unfamiliar or very familiar with the correlation between 1) moving the crash cart close to the room prevents a code from happening, 2) opening a window to let a soul leave, giving permission to die, and 3) not opening a sterile package preventing the need for the procedure. Within the PR items, unfamiliar or very familiar varied between the study population as a whole and those that identified themselves as superstitious for 1) never mentioning a frequent flyer by name to avoid them showing up and 2) not saying "see you soon" when dismissing a patient to prevent a re-admission. A similar bi-modal change was noted within the SC sub-section, responses from superstitious participants on the item that assessed bringing something to work will result in a busy shift was also described as unfamiliar or very familiar by this population, when compared to the study participants as a whole.

Comparing responses between the entire study population to those of participants who self-described themselves as superstitious was also undertaken. Using the same format, differences greater than $5 \%$, while not statistically significant, were identified as trends. Analyses of these data reveal that participants who selfdescribed themselves as superstitious perceived each item on the survey to be very relevant. When comparing the responses indicating the item to be irrelevant, the responses decreased by a mean of $17.9 \%$ (range $7.6 \%-57.8 \%$ ). The item with the least irrelevance variance when compared to the study population as a whole described tying a knot in the bedsheet to keep the patient from dying $(-7.6 \%)$. This item also achieved the least very relevant variance $(+1.4 \%)$ between the two study populations. Breaking a mirror causes 7 years of bad luck was identified as irrelevant for $73.6 \%$ of the study population as a whole, yet only $18.5 \%$ of those self-identifying as being superstitious described this item as irre- 
levant; a difference of $57.8 \%$.

In summary, while several items within the level of familiarity aspect of the survey was perceived differently, based on one's belief in superstitions, each item was perceived to have greater relevance to clinical practice among those participants who described themselves as superstitious. While superstitions are relevant to clinical practice, they are embraced among those who, as a general rule, described themselves as superstitious.

The clinical situation during the data collection timeframe was rife with uncertainty, an increase in patient census, and care acuity levels that were higher than routine, with treatment options few and untested. Thus, a focus on events that cannot be controlled, including death, existed. Analyses specific to the survey items that reflect death and dying (death comes in threes, moving the crash cart, tying a knot, printing the death package) seemed appropriate. The result of this focused analysis identified the item describing tying the knot in the bedsheet to keep the patient from dying was unfamiliar to $85.1 \%$ of participants who believed in superstitions and $82 \%$ of participants who did not believe in superstitions. Unfamiliarity with this item was reported by $9.2 \%$ of those who believe in superstitions and $10.8 \%$ of those who do not. Responses to this item demonstrated a general agreement on being clinically irrelevant by $86 \%$ of those who believe in superstitions, and $82 \%$ of those that do not, and being very relevant for $2.9 \%$ of the study population who believes in superstitions, and $4.3 \%$ of those that do not believe in superstitions. Knowledge of this superstition appears to correlate to its clinical relevancy, regardless of one's personal superstition status.

\section{Conclusion}

Data from this study describe the knowledge and relevance to clinical practice of superstitions among nursing staff who provided direct patient care during a pandemic. The use of superstitions to explain and minimize the fear of the unknown, as described by Taher et al. (2020), together with the multitude of items focused on death, illness, or adverse events, is supported by the results of this study. The relationship between a person's self-reported superstitious and the likelihood of these superstitions guiding behavior, as outlined by Griffiths et al. (2019), was apparent by these data which compared responses of those self-describing themselves as superstitious to the study population as a whole.

Demographically, differences were noted between these results and the research literature. While these participants were not athletics, gender-specific differences were not identified, neither were age differences. Education and age did tend to decrease the relevance of superstitions, which varies from the conclusions of research by Ramezani et al. (2016) and Torgler (2007). The relevance of each superstition to clinical practice varied, yet the ability of these participants to articulate any superstition as relevant correlates to an atmosphere of acceptance. Positing that, if a superstition is relevant to one's clinical practice, the behavior described in the item would occur. Acting on a superstitious belief has not been 
linked to care outcomes, rendering these activities harmless to the patient, yet beneficial to the care provider.

Institutional policies, specifically those that guide the placement of equipment, care interventions, communication between the care provider and the patient, and/or when forms or packets should be readied, should remain flexible. This flexibility supports the care providers' need for superstitions to provide a psychological cognitive benefit. As coping mechanisms, superstitions are culturally specific and have documented effectiveness for understanding events that cannot be controlled. If their use during the COVID-19 pandemic provided a therapeutic benefit for direct care providers, and any perceived control over the challenging circumstances, superstitions should be embraced and supported.

\section{Conflicts of Interest}

The authors declare no conflicts of interest regarding the publication of this paper.

\section{References}

Abredari, H., Bolourchifard. F., Rassouli. M., Nasiri, N., Taher, M., \& Abedi A. (2015). Health Locus of Control and Self-Care Behaviors in Diabetic Foot Patients. Medical Journal of the Islam Republic of Iran, 29, 283-287.

Buhrmann, H. G., \& Zuagg, M. (1981). Superstitions among Basketball Players an Investigation of Various Forms of Superstitious Belief and Behavior among Competitive Basketballers at the Junior High School to University Level. Journal of Sports Behavior, 4, 163 175.

Carlson, B. D., Mowen, J. C., \& Fang, X. (2009). Trait Superstition and Consumer Behavior: Re-Conceptualization, Measurement, and Initial Investigations. Psychology \& Marketing, 26, 689-713. https://doi.org/10.1002/mar.20295

Chukkali, S., \& Dey, A. M. (2020). Development and Validation of Superstitious Beliefs Scale. Rupkatha Journal on Interdisciplinary Studies in Humanities, 12, 1-12. https://doi.org/10.21659/rupkatha.v12n1.32

Faiza, A. (2018). Social and Psychological Factors for Superstition: A Brief Literature Review. International Journal of Advanced Study and Research Work, 1, 1-6.

Griffiths, O., Shehabi, N., Murphy, R. A., \& LePelly, M. E. (2019). Superstition Predicts Perception of Illusory Control. British Journal of Psychology, 110, 499-518. https://doi.org/10.1111/bjop.12344

Hirshleifer, D., Jian, M., \& Zhang, H. (2018). Superstition and Financial Decision-Making. Manage Science, 64, 232-252. https://doi.org/10.1287/mnsc.2016.2584

Hong, S. J. (2018). Gendered Cultural Identities: The Influences of Family and Privacy Boundaries, Subjective Norms, and Stigma Beliefs on Family Health History Communication. Health Communication, 33, 927-938. https://doi.org/10.1080/10410236.2017.1322480

Huque, M., \& Huq Chowdhurry A. (2007). A Scale to Measure Superstition. Journal of Social Science, 3, 18-23.

Kashdan, T. B., \& Rottenberg, J. (2010). Psychological Flexibility as a Fundamental Aspect of Health. Clinical Psychology Review, 30, 865-878.

https://doi.org/10.1016/j.cpr.2010.03.001 
Kuhl, D. (2003). What Dying People Want: Practical Wisdom for the End of Life. Public Affairs.

Matute, H., Yarritu, I., \& Vadillo, M. A. (2011). Illusions of Causality at the Heart of Pseudoscience. British Journal of Psychology, 102, 392-405. https://doi.org/10.1348/000712610X532210

Neil, G., Anderson, B., \& Sheppard, W. (1981). Superstitions among Male and Female Athletes at Various Levels of Involvement. Journal of Sport Behavior, 4, 137-148.

Omeje, O., \& Nebo, C. (2011). The Influence of Locus Control on Adherence to Treatment Regimen among Hypertensive Patients. Patient Prefer Adherence, 5, 141-148. https://doi.org/10.2147/PPA.S15098

Parnell, J. A., Dent, E. B., O’Regan, N., \& Hughes, T. (2012). Managing Performance in a Volatile Environment: Contrasting Perspectives on Luck and Causality. British Journal of Management, 23, S104-S118. https://doi.org/10.1111/j.1467-8551.2012.00815.x

Peterson, C. (1978). Locus of Control and Belief in Self-Oriented Superstitions. The Journal of Social Psychology, 105, 305-306. https://doi.org/10.1080/00224545.1978.9924131

Phillips, D., \& Clancy, K. (1972). Some Effects of "Social Desirability” in Survey Studies. American Journal of Sociology, 77, 921-940. https://doi.org/10.1086/225231

Ramezani, K., Ramezanu, M., \& Ramezani, Z. (2016). Comparison of the Trend of Superstition in Educated Academics and Commons Kohgiluyeh and Boyer-Admad. International Journal of Humanities and Cultural Studies, 3, 496-510.

Skinner, B. F. (1953). Science and Human Behavior. Macmillan.

Stapelberg, M. (2014). Strange but True. Crux Publishers.

Taher, M., Pashaeypoor, S., Cheraghi, M. A., Karimy, M., \& Hoseini, A. S. S. (2020). Superstition in Health Beliefs: Concept Exploration and Development. Journal of Family Medicine and Primary Care, 9, 1325-1330. https://doi.org/10.4103/jfmpc.jfmpc $871 \quad 19$

Taher, M., Safavi Bayat, Z., Ghasemi, E., Abredari, H., Karimy, M., \& Abedi, A. R. (2015). Correlation between Compliance Regimens with Health Locus of Control in Patients with Hypertension. Medical Journal of Islam Republic of Iran, 29, 194-196.

Torgler, B. (2007). Determinants of Superstition. The Journal of Socio-Economics, 36, 713733. https://doi.org/10.1016/j.socec.2007.01.007

Vyse, S.A. (1997). Believing in Magic: The Psychology of Superstition. Oxford University Press.

Whitson, J. A., \& Galinsky, J. D. (2008). Lacking Control Increases Illusionary Pattern Perception. Science, 322, 115-117. https://doi.org/10.1126/science.1159845

Wong, S. H. (2012). Does Superstition help? A Study of the Role of Superstitions and Death Beliefs on Death Anxiety Amongst Chinese Undergraduates in Hong Kong. Omega, 65, 55-70. https://doi.org/10.2190/OM.65.1.d 